\section{Effect of Aging on Dentinal Crack Formation a f e r Treatment and Retreatment Procedures: a Micro-CT Study}

Lilian Rachel de Lima Aboud ${ }^{1}$, Bernardo Camargo dos Santos², Ricardo Tadeu Lopes ${ }^{2}$, Leonardo Aboud Costa Viana ${ }^{1}$, Miriam Fátima Zaccaro Scelza ${ }^{1}$
'Department of Endodontics and Geriatric Dentistry, UFF - Universidade Federal Fluminsense Niteroi, RJ, Brazil ${ }^{2}$ Department of Nuclear Energy, UFRJ - Universidade Federal do Rio de Janeiro, Rio de Janeiro, RJ, Brazil

Correspondence: Miriam Fátima Zaccaro Scelza, Rua Mario Santos Braga, 30, $3^{\circ}$ andar, 24020140 Niteroi, Rio de Janeiro, RJ, Brasil. Tel: + 55-21-2629-9835. e-mail: scelza@terra.com.br

\begin{abstract}
In order to evaluate the volume of dentinal cracks taking into account the age of the dentin and the type of file system used for endodontic procedures, forty freshly extracted single-rooted lower incisive teeth presenting similar root volume, were divided into two groups according to the age of the patient: Group Young (18 - 30 years old) and Group Old (60 years old or more). Each specimen was scanned by microcomputed tomography (micro-CT) in three stages: (i) before any treatment, (ii) after endodontic treatment with Reciproc files (REC), and (iii) after subsequent endodontic retreatment. Each group was subdivided into two subgroups, according to the retreatment technique used: retreatment with REC or with ProTaper Universal Retreatment (PUR) files. For each subgroup, the images were analyzed for differences in the volume of dentinal cracks in the middle and apical thirds of the teeth, according to the dentin age. In both stages (before and after instrumentation), the micro-CT images of the old root dentin presented with higher volume of cracks than those of the young root dentin, statistical significance notwithstanding $(p>0.01)$. The use of REC files appeared to have no statistically significant differences in the generation of cracks in any type of root dentin when compared with PUR files $(p>0.01)$. When retreated with PUR, the old root dentin presented with a significantly higher volume of cracks $(p<0.01)$ when compared with the old root dentin initially.
\end{abstract}

Key Words: dentinal age, dentinal volume cracks, microcomputed tomography, reciprocating files, rotary files

\section{Introduction}

It is well known that the human dentin undergoes various modifications, such as decrease in the number and size of dentinal tubule with age (1), thereby lowering the incidence of bacterial infections in the tubules (2). The young hydrated dentin presents with certain mechanisms that contribute to the dissipation of energy and resistance to the development of cracks on the surface, a feature that is absent in the aged dentin, as the crack resistance of human dentin decreases with tissue age and dehydration $(3,4)$. Therefore, studies on the effect of different types of endodontic procedures on the dentin, according to dentinal age, would be relevant in daily clinical practice.

Dentinal cracks may occur due to the amount of dentin removed during endodontic treatment and retreatment procedures. Moreover, different files systems, with various tapers, cutting blades and tip configurations, including manual, rotary and reciprocating motion instrumentation, are used. Several studies have reported that manual and reciprocating motion instruments can generate cracks, but on a smaller scale when compared with the rotating files (5-7).

In the case of endodontic retreatment, researchers reported the incidence of crack formation and propagation after the procedure with manual, rotational and reciprocating instruments. The behavior of rotational and reciprocating systems in the generation of defects has been the point of greatest interest in these studies (8-12).

Different microscopy methods have been used to analyze dentinal defects (9). Microcomputed tomography (micro-CT) imaging provides accurate details of defects in dentin at high-resolution $(9,10)$. Regardless of the type of instrumentation, this technique can depict the generation and amount of crack formation after endodontic treatment and retreatment, thus providing a clear insight into how the different files, techniques and systems used can influence endodontic success or failure (8-10).

This study compared the increase in the volume of crack formations in young and old root dentin, before and after endodontic treatment and retreatment with rotary and reciprocating instruments, using micro-CT analysis. The Reciproc file (REC; VDW, Munich, Germany) was used for canal instrumentation. In the retreatment stage both groups were divided and retreated with REC and ProTaper Universal Retreatment file (PUR; Dentsply Maillefer, Ballaigues, Switzerland) with the aim of comparing the two systems in both dentin (young and old), by using micro-CT analysis.

\section{Material and Methods}

Selection of Samples and Micro-CT Specifications

According to a statistical database, the number of 
samples was selected after obtaining the approval of the Ethics Committee of the Federal Fluminense University, Niterói, Brazil (local ethical committee review number 40186714.5.0000.5243). Forty freshly extracted mandibular single-rooted human teeth were selected and stored in artificial saliva at $37^{\circ} \mathrm{C}$ throughout the experimental procedures. The chosen teeth were lower incisive that presented similar root volume, in order to standardize the maximum of the present research. Teeth with root fractures, curved canals, multiple roots, caries or restorations, severe anatomic variations, and severe calcified canals were excluded. The teeth were divided into two groups (Table 1): Group Y, teeth belonging to patients aged $18-30$ years old $(n=20)$; and Group 0, teeth obtained from patients aged 60 years or more $(n=20)$. A micro-CT scanner (Skyscan 1173; Brucker micro-CT, Kontich, Belgium) at $70 \mathrm{kV}$ and $114 \mathrm{~mA}$ was used in this study to evaluate the dentinal cracks. A total of 449 micro-CT slices (thickness, 14. 25 $\mu \mathrm{m}$ each) were analyzed from samples of the apical and middle thirds of the teeth. Thus, a profile of approximately $15 \mathrm{~mm}$ from the apex of the root was obtained. A specific metal support was used and an acrylic resin base was made so that each dental specimen remains securely fitted for further observations.

The presence of previous cracks in some of the forty teeth was identified by an initial micro-CT analysis performed in all dental elements prior to the endodontic treatment. Then, both groups of teeth were endodontically treated.

\section{Root Canal Preparation}

Before initiating the endodontic treatment, the surface of the roots was coated with a polyether-based impression material (Impregum F, 3M ESPE, St Paul MN, Germany) in order to simulate the periodontal ligament space. Then, it was embedded in a base made of epoxy resin (diameter $18 \mathrm{~mm}$ ) (11).

To ensure standardization, the teeth were accessed and patency was performed with a \#15 K file (Dentsply Sirona, Ballaigues, Switzerland) accompanied by abundant irrigation-aspiration with 5.25\% sodium hypochlorite ( $\mathrm{NaOCl}$; Formula e Ação Farmácia, São Paulo, SP, Brazil) throughout the instrumentation process. All specimens were instrumented with Reciproc R.25 file with a 0.08 taper (VDW, Munich, Germany), to achieve a previously standardized shape, using the motor VDW SILVER RECIPROC ${ }^{\circledR}$ (VDW, Munich, Germany) according to manufacturer's standards. After instrumentation, copious irrigation was performed with a total of $30 \mathrm{~mL}$ of $\mathrm{NaOCl}$, followed by a final rinse with $10 \mathrm{~mL}$ of 10\% citric acid (Formula e Ação Farmácia) and $5 \mathrm{~mL}$ of double distilled water.

Subsequently, all forty samples were separated according to age, and analyzed for the second time by micro-CT to assess whether the instrumentation had generated some damage to the dentin prior to the endodontic retreatment.

\section{Root Canal Filling}

After the micro-CT second analysis, the specimens were irrigated with $5.25 \% \mathrm{NaOCl}$ and $10 \%$ citric acid and dried with Reciproc R.25 paper cones (VDW). The canals were filled with Reciproc R.25 gutta-percha (VDW) and AH Plus sealer (Dentsply De Trey, Konstanz, Germany) using the warm vertical compaction technique (Easy Thermo-Pack, Easy Endo, Belo Horizonte, Brazil) in order to cause less impact on the root and reduce the risk of crack formation at this stage (11). Coronal sealing was carried out with a temporary sealer Coltosol ${ }^{\circledR}$ (Vigodent, Rio de Janeiro, RJ, Brazil). The teeth were immersed in artificial saliva at $37^{\circ} \mathrm{C}$ for 30 days.

\section{Sample Groups}

As shown in Table 1, after root canal filling, the samples were separated into the subgroups based on the retreatment technique used:YR (young retreated with Reciproc), YP (young retreated with ProTaper Universal Retreatment), OR (old retreated with Reciproc), and OP (old retreated with ProTaper Universal Retreatment).

The YR and $O R$ subgroups were retreated with file Reciproc R.25. The bulk of the gutta-percha in the coronal third of the canal was removed with an electric heat carrier (Easy Thermo-Pack, Easy Endo, Belo Horizonte, Brazil). The REC file was introduced into the canal in a slow in-and-out pecking motion applying slight pressure, without pulling the instrument completely out of the canal or advancing into the filling material toward the apical third. The samples

Table 1 . Separation of teeth by groups according to the retreatment technique

\begin{tabular}{cc} 
Group Y & $\begin{array}{c}\text { Group 0 } \\
\text { Teeth of 18-30-year-old patients }(\mathrm{n}=20)\end{array}$ \\
\hline Group YR: Teeth retreated with Reciproc R.25 $(\mathrm{n}=10)$ & Troup OR: Teeth retreated with Reciproc R.25 (n = 10) \\
Group YP: Teeth retreated with Protaper D1, D2 and D3 ( $\mathrm{n}=10)$ & Group OP: Teeth retreated with Protaper D1, D2 and D3 (n = 10) \\
\hline
\end{tabular}

Groups: Y (Young), YR (Young retreated with Reciproc), YP (Young retreated with ProTaper Universal Retreatment), 0 (Old), OR (Old retreated with Reciproc), OP (Old retreated with ProTaper Universal Retreatment). 
were irrigated with a total of $30 \mathrm{~mL} 5.25 \% \mathrm{NaOCl}, 10 \mathrm{ml}$ $10 \%$ citric acid and $5 \mathrm{~mL}$ double distilled water. Hence, a total solution volume of $45 \mathrm{~mL}$ was used per root canal. Coronal sealing was carried out with Coltosol ${ }^{\circledR}$.

The YP and OP subgroups were retreated with PUR files. An initial penetration of the filling material was made with a D1 file, followed by a sequence of penetrations with the shortest to the longest file (D1, D2, D3), applying slight apical pressure. The speed of the motor VDW was 600 $\mathrm{rpm}$. The specimens were irrigated and coronal sealing was performed similar to the YR and OR subgroups.

After the last step, the teeth were submitted to a third micro-CT analysis to detect the volume of cracks according to the instrument used for endodontic retreatment, and taking into consideration the age of the dentin.

\section{Dentinal Crack Evaluation}

Four hundred and forty nine frames (thickness 14.25 $\mu \mathrm{m})$, obtained from the medium and apical thirds of the root of each tooth, were evaluated. Frame integration functions of the CTA-n (Brucker micro-CT, Kontich, Belgium) and Image Pro Plus 7.0 software (Media Cybernetics, Bethesda, USA) were used for to assess crack formation. The use of said softwares allows the visualization of animated images along the axis of the tooth, from the start of crack formation to the end. The software ImageJ $1.49 \mathrm{~m}$ (National Institute of Health, Bethesda, USA) was used to segment and quantify the volume of cracks.

\section{Statistical Analysis}

Statistical analysis was performed with Prism 5 software

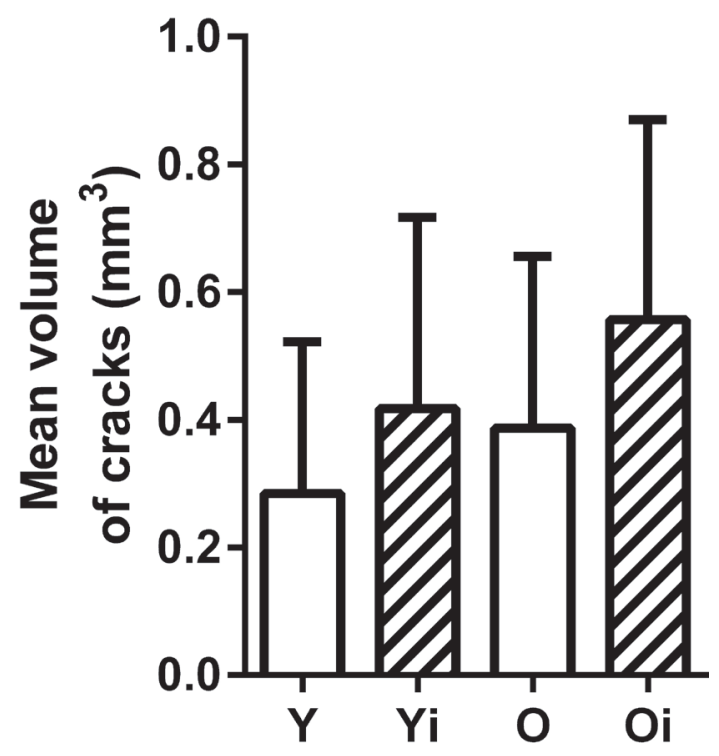

Figure 1. The mean volume of cracks $\left(\mathrm{mm}^{3}\right)$ in the different groups: $\mathrm{Y}$ and $\mathrm{O}$ (white bars) before instrumentation; $\mathrm{Yi}$ and $\mathrm{Oi}$ (striped bars) after instrumentation, $(p>.01)$, with no significant difference.
(Graph Pad Software, La Jolla, USA). The Mann-Whitney test method was used with significance level of $1 \%$ in order to compare the mean volume of cracks between non-instrumented and instrumented young and old root dentin, and between young and old dentin retreated with REC and PUR.

Friedman's test was employed together with Dunn's multiple comparisons post-test in order to compare the incidence of crack formation throughout the interventions when using the two different types of files. Mann-Whitney test was used at each moment to compare the number of cracks among the young and old dentin and REC and PUR cases.

\section{Results}

Initial analysis of the dental elements before any intervention showed that Group 0 presented with a mean crack volume of $0.39 \mathrm{~mm}^{3}$, whereas mean volume in Group $Y$ was $0.28 \mathrm{~mm}^{3}$, statistical significance notwithstanding ( $p>0.01$ ). In the second analysis (micro-CT), after endodontic treatment with REC files and before the root canal filling, the specimens demonstrated a no significant statistical increase in the volume of the cracks ( $p>0.01$ ), between the Old instrumented (Oi) group and Young instrumented (Yi) group (0.42 $\mathrm{mm}^{3}$; Fig. 1).

In the third analysis (micro-CT) after retreatment, no significant differences were observed in the incidence of cracks among the YR, YP, OR and OP groups ( $p>0.01$; Fig. 2 ).

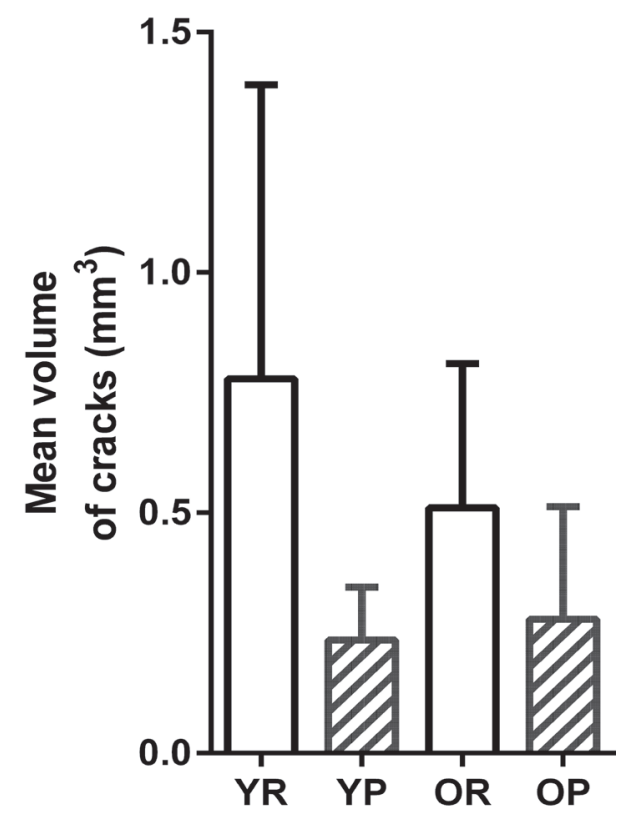

Figure 2. Mean volume of cracks $\left(\mathrm{mm}^{3}\right)$ after retreatment with the REC (white bars) and PUR (striped bar) instruments, $(p>$.01).with no significant difference. 
As shown in Figure 3, analysis of the volume of microfractures throughout the interventions revealed significant statistical differences $(p<0.01)$ between group 0 and group OP $\left(0.017 \pm 0.008 \mathrm{~mm}^{3}\right.$ vs $\left.0.045 \pm 0.021 \mathrm{~mm}^{3}\right)$.

Figure 4 illustrates the cracks in an young and old dentin retreated with REC and PUR after the retreatment procedure. The arrow indicates the cracks presents. .

\section{Discussion}

To the best of our knowledge, this is the first ex-vivo study to compare the volume dentinal cracks between young and old root dentin after instrumentation and endodontic retreatment. Micro-CT technology allows for a detailed analysis of the roots before any endodontic procedure is performed $(9-10,13)$. In the initial analysis before any intervention in the present study, Group 0 presented a tendency to have a higher volume of cracks than the $Y$ group, but it was not statistically significant $(p>0.01)$. The old root dentin presented changes in the structural dentin with degradation in the fibril collagen network (3). Moreover, it tends to be more dehydrated, thus reducing the dissipation of energy, causing it to become more fragile and susceptible to micro-cracks $(3,4,14)$.

The use of single-rooted mandibular incisive teeth attempted to decrease variations in study results. Storage
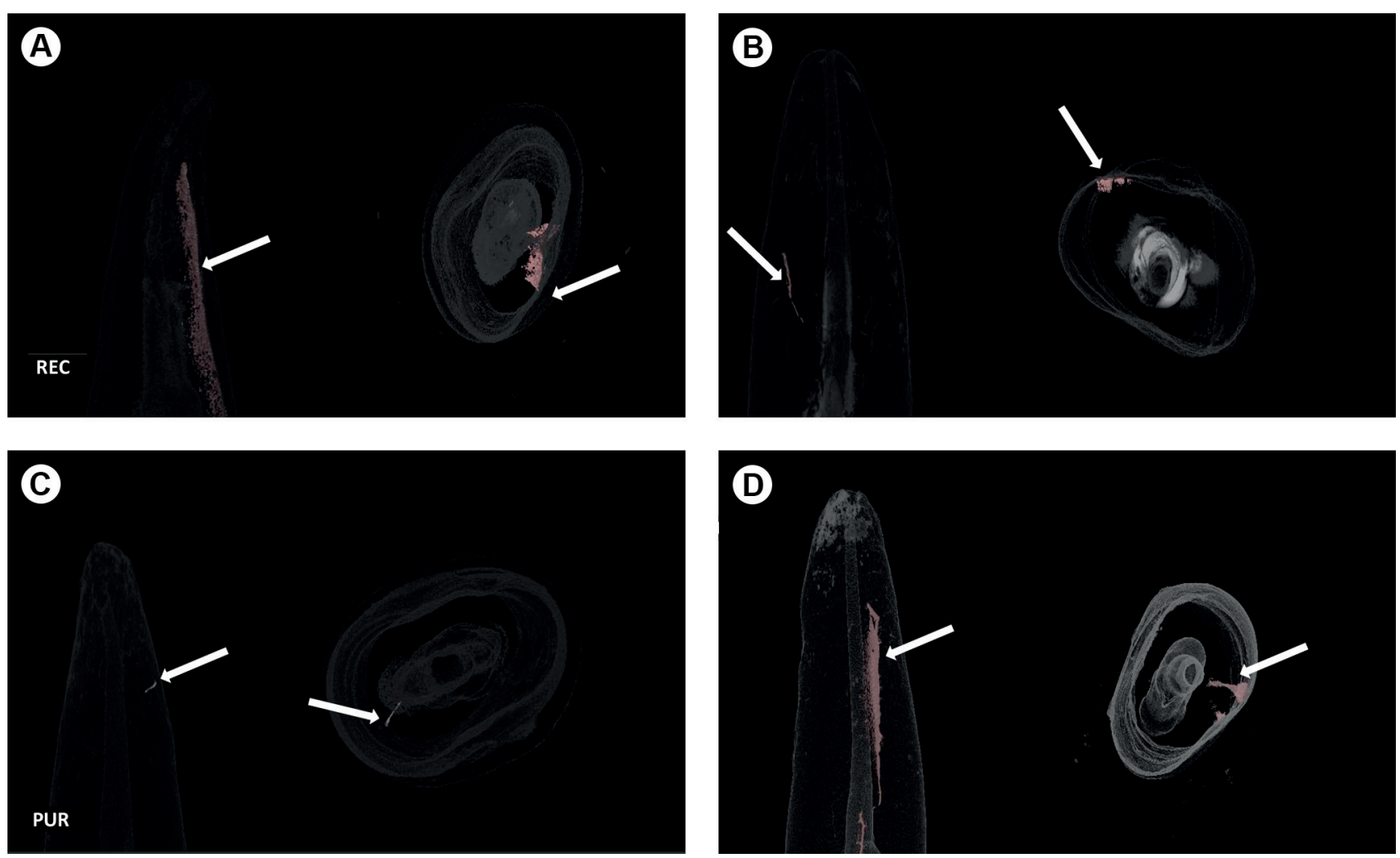

conditions are known to affect the incidence of dentinal cracks before and during endodontic procedures $(11,15)$. In the present study, dental specimens were stored in artificial saliva at $37^{\circ} \mathrm{C}$ throughout the study period as they needed to be well hydrated, simulating clinical circumstances. Another means of minimizing the effect of defect-causing factors is by simulating the periodontal ligament, by attaching

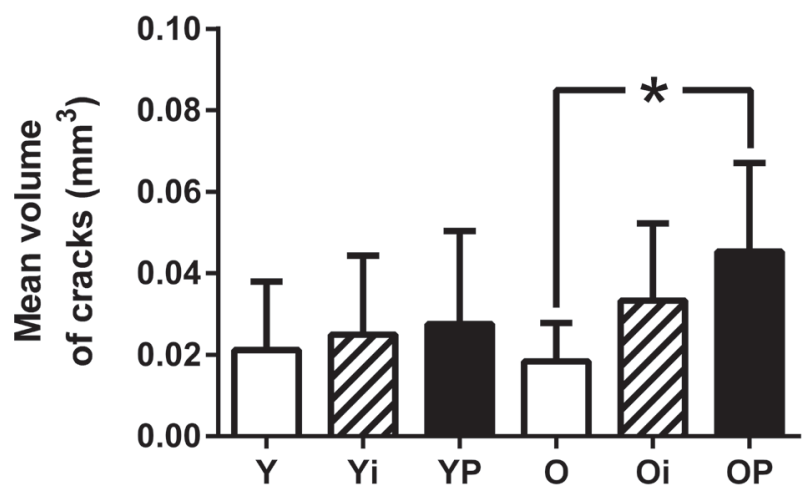

Figure 3. Evolution of the mean crack volumes $\left(\mathrm{mm}^{3}\right)$ in the groups: $\mathrm{Y}$ and $\mathrm{O}$ (white bars, before instrumentation), Yi and Oi (striped bars, after instrumentation) and YP and OP (black bars, retreated with PUR files). The "**" shows the significant difference statistical between 0 and $\mathrm{OP}(\mathrm{p}<0.01)$. Among the other groups, there was no statistical difference $(p>0.01)$.

Figure 4. The mean volume of cracks in 3D images, in the different groups, indicates by arrow: A (Crack Y dentin after retreatment with REC), B (Crack 0 dentin after retreatment with REC), C (Crack Y dentin after retreatment with PUR), D (Crack 0 dentin after retreatment with PUR). 
the dental element to a base made of epoxy resin through a molding polyether material, in order to neutralize the impact on the dentin during the endodontic procedures (11). Additionally, the use of irrigating substances during the endodontic process can also induce defects. $\mathrm{NaOCl}$ can induce more defects in the dentinal surface (16) than the ones induced by EDTA. Final irrigation with 10\% citric acid was chosen in this study because EDTA (17\%) has showed up to induce significant demineralization in old root dentin (14). Lastly, the effect of rotary and reciprocating systems files on the incidence of dentinal defects during endodontic procedures has been reported in the literature, some cases with no significance on the formation regardless of the technique or instrument used $(6,11,15,17)$.

In order to minimize the increase in the volume of dentinal defects, instrumentation was performed using the single-file system (Reciproc R.25 in both groups) because the sample used presented with the same shape and root curvature suitable for this file. The REC files were chosen because of their flexibility, consequence of the fact that they are made of M-Wire Nickel-Titanium alloy subjected to thermal treatment with an S-shaped cross-section, which can reduce the incidence of cracks when compared with the rotary system $(11,18,19)$. The results of the present study showed that the specimens presented with an increase in the volume of cracks, although the difference was not statistically significant $(p>0.01)$. This is in accordance with the findings of previous studies, thus indicating that instrumentation with REC may cause damage to the dentin $(6,15)$. The old root dentin demonstrated an increasing trend in the volume of cracks when compared with the young dentin, which may be attributed to the physiological conditions of the aged dentin $(3,4,14)$.

Some studies have reported that filling techniques can cause dentinal fissures mainly due to the forces applied at the moment of vertical compaction $(20,21)$. De Deus et al. (21) studied different techniques of root canal filling, in order to verify the formation of cracks, using micro-CT. The results showed that no have effect on the generation or increase in volume of crack formation, including the warm vertical compaction. Therefore, warm vertical compaction was the method of choice during the tooth filling stage of posterior retreatment.

In this study, the choice of REC and PUR files for endodontic retreatment was based on previous literature, which showed the efficiency of these files in the generation or increase of dentinal defects. The REC and PUR systems require short periods of time for retreatment, both are safe for the removal of fillings in straight root canals and are associated with the formation of dentinal defects during the retreatment procedure $(14,22,23)$. Liu et al. (11) report in their study that the system that uses a single file, like
Reciproc, is able to generate less dentin defects than the system that uses multiple files, like ProTaper. However, is noteworthy that PUR files have three instruments with particular designs, wherein each one has an active tip to facilitate the initial tooth penetration and the removal of the filling material (24).

After retreatment with REC and PUR, visualization by micro-CT revealed no statistically significant difference in the volume of crack formation between the YR and YP groups ( $p>0.01)$. However, a significant difference $(p<0.01)$ was noted when the PUR file was used for retreatment in the OP group when compared with Group 0 . This evidence has supported the argument that the REC file is less aggressive to the dentin during retreatment (24) when compared with the PUR file (25). In addition, as the dentin tends to become more fragile with age, it may present with more defects when submitted to endodontic procedures $(1-4,12)$. Considering these factors, the present study showed that the REC files were not prejudicial to any of the root dentin. Nevertheless, further studies confirming these results are merited.

Within the limitations of the present study, the use of REC files appeared to have no statistically significant differences in the generation of cracks in any type of root dentin when compared with the PUR files. Significant increase in the volume of crack formation was noted in the old root dentin following retreatment with PUR. The present study may contribute to clinical practice during endodontic procedures in patients of different ages.

\section{Acknowledgements}

The authors deny any conflict of interest related to this study. Aboud, LRL has grants from Nuclear Instrumentation Laboratory - COPPE/UFRJ, Rio de Janeiro, Brazil; and National Commission for Nuclear Energy-CNEN, Rio de Janeiro, Brazil.

\section{Resumo}

Para avaliar o volume de fissuras dentinárias levando em consideração a idade da dentina e o tipo de sistema de limas utilizadas para procedimentos endodônticos, 40 dentes unirradiculares, incisivos inferiores, apresentando similar volume radicular, recentemente extraídos foram divididos em dois grupos de acordo com a idade do paciente: Grupo Jovem (18 a 30 anos) e Grupo Idoso (60 anos ou mais). Cada espécime foi scaneada por microtomografia computadorizada (micro-CT) em três estágios: (i) antes de qualquer tratamento, (ii) após tratamento endodôntico com limas Reciproc (REC) e (iii) após subsequente retratamento endodôntico. Cada grupo foi subdividido em dois subgrupos, de acordo com a técnica de retratamento utilizada: retratamento com REC ou com lima ProTaper Universal Retreatment (PUR). As imagens foram analisadas quanto às diferenças no volume das fissuras dentinárias nos terços médio e apical dos dentes de acordo com a idade da dentina. Em ambos os estágios (antes e depois da instrumentação), as imagens de micro-CT da dentina radicular idosa apresentaram maior volume de trincas do que as jovens, sem significância estatística ( $p>0.01$ ). 0 uso das limas REC mostram não ter diferença estatística significante na geração de fissuras, em qualquer tipo de dentina, quando comparadas às limas PUR ( $p>0.01)$. Quando retratada com PUR, a dentina radicular idosa apresentou um volume de trincas significativamente maior $(p<0.01)$ quando comparado com a dentina radicular idosa inicialmente. 


\section{References}

1. Kontakiotis EG, Tsatsoulis IN, Filippatos CG, Agrafioti A. A quantitative and diametral analysis of human dentinal tubules at pulp chamber ceiling and floor under scanning electron microscopy. Australian Endod J 2015;42: 29-34.

2. Kakoli P, Nandakumar R, Romberg E, Arola, D, Fouad A. The effect of age on bacterial penetration of radicular dentin. J Endod 2009; 35:78-81.

3. Bajaj D, Sundaram N, Nazari A, Arola D. Age, dehydration and fatigue crack growth in dentin. Biomaterials 2006; 27:2507-2517.

4. Eldarrat $\mathrm{AH}$, High $\mathrm{AS}$, Kale GM. Age-related changes in ac-impedance spectroscopy studies of normal human dentine: further investigations. J Mater Sci Mater Med 2010;21:45-51.

5. Kumari MR, Krishnaswamy MM, Manjunath M. Comparative analysis of crack propagation in roots with hand and rotary instruments of the root canal-an ex-vivo study. J Clin and diag research 2016; 10:16-19.

6. Kansal R, Rajput A, Talwar S, Roongta R, Verma M. Assessment of dentinal damage during canal preparation using reciprocating and rotary files. J Endod 2014;40:1443-46.

7. Ahn SY, Kim HC, Kim E. Kinematic effects of nickel-titanium instruments with reciprocating or continuous rotation motion: a systematic review of in vitro studies. J Endod 2016;42:1009-1017.

8. Özyürek Taha Tek Vildan; Yılmaz Koray, Uslu Gülşah. Incidence of apical crack formation and propagation during removal of root canal filling materials with different engine driven nickel-titanium instruments. Restorative Dentistry \& Endodontics. 2017; 42:332-341.

9. Pop I, Manoharan A, Zanini F, Tromba G, Patel S, Foschi F. Synchrotron light-based $\mu \mathrm{CT}$ to analyse the presence of dentinal microcracks post-rotary and reciprocating $\mathrm{NiTi}$ instrumentation. Clinical Oral Investigations 2015;19:11-16.

10. Ceyhanli K T, Erdilek N, Tatar I, Celik D. Comparison of ProTaper, RaCe and Safesider instruments in the induction of dentinal microcracks: a micro-CT study. Int Endod J 2016;49 684-689.

11. Liu R, Hou BX, Wesselink PR, Wu LK, Shemesh K. The incidence of root microcracks caused by 3 different single-file systems versus the ProTaper system. J Endod 2013;39: 1054-1056.

12. Shemesh $H$, Bier CA, Wu MK, Tanomaru-Filho M, Wesselink PR. The effects of canal preparation and filling on the incidence of dentinal defects. Int Endod J 2009; 42:208-213.

13. Ustun $Y$. The effects of different nickel-titanium instruments on dentinal microcrack formations during root canal preparation. Eur journal of dentistry 2015;9:41.

14. Scelza MFZ, Noronha F, Silva, LE, Mauricio M, Gallito MA, Scelza
P. Effect of citric acid and ethylenediaminetetraacetic acid on the surface morphology of young and old root dentin. Iranian Endod J 2016;11:188-191.

15. Bürklein $\mathrm{S}$, Tsotsis $\mathrm{P}$, Schäfer $\mathrm{E}$. Incidence of dentinal defects after root canal preparation: Reciprocating versus rotary instrumentation. J Endod 2013; 39:501-504.

16. Adl A, Sedigh-Shams M, Majd M. The effect of using RC Prep during root canal preparation on the incidences of dentinal defects. J Endod 2015;41:376-379.

17. Yoldas O, Yilmaz S, Atakan G, Kuden C, Kasan C. Dentinal microcrack formation during root canal preparations by different NiTi rotary instruments and the Self-Adjusting File. J Endod 2012;38:232-235

18. Varela-Platino P, Ibanez PA, Rivas MB, Cantatori G, Otero XL, MartinBiedma B. Alternating versus continuous rotation: a comparative study of the effect on instrument life. J Endod 2010;36:157-159.

19. Pedullà E, Genovesi F, Rapisarda S, La Rosa GR, Grande NM, Plotino G, et al. Effects of 6 single-file systems on dentinal crack formation. J Endod 2017;43:456-461.

20. De-Deus G, Belladonna FG, Silva EJ, Souza EM, Carvalhal JCA, Perez R, et al. Micro-CT assessment of dentinal micro-cracks after root canal filling procedures. Int Endod J 2016;1-6.

21. Barreto MS, Moraes Rdo A, Rosa RA, Moreira CH, Bier CA. Vertical root fractures and dentin defects: effects of root canal preparation, filling, and mechanical cycling. J Endod 2012;38: 1135-1139.

22. Akbulut MB, Akman M, Terlemez A, Magat G, Sener S, Shetty H. Efficacy of Twisted File Adaptive, Reciproc and ProTaper Universal Retreatment instruments for root-canal-filling removal: A cone-beam computed tomography study. Dental Materials J 2016;35:126-131.

23. Çanakçi BC, Ustun Y, Er O, Sen OG. Evaluation of apically extruted debris from curved root canal filling removal using 5 nickel-titanium systems. J Endod 2016; 42:1101-1104.

24. De-Deus G, Silva EJNL, Marins J, Souza E, Neves AA, Golçalves BF, et al. Lack of causal relationship between dentinal microcracks and root canal preparation with reciprocation systems. J Endod 2014; 40:14471450.

25. Li SH, Lu Y, Song D, Zhouu X, Zheng $\mathrm{QH}, \mathrm{Gao}, \mathrm{Y}$, et al. Occurrence of dentinal microcracks in severely curved root canals with ProTaper Universal, WaveOne, and ProTaper Next file systems. J Endod 2015; 41:1875-1879.

Received December 7, 2017 Accepted July 30, 2018 